\title{
Effective Mediastinal Lymphadenectomy for Esophageal Cancer Using Slender Tracheal Forceps in Prone Position Thoracoscopic Esophagectomy
}

\author{
MASANOBU NAKAJIMA ${ }^{1}$, MASAKAZU TAKAHASHI ${ }^{1}$, YASUSHI DOMEKI ${ }^{1}$, HITOSHI SATOMURA $^{1}$, \\ HIROTO MUROI ${ }^{1}$, MAIKO KIKUCHI ${ }^{1}$, HIDEO OGATA $^{1}$, SATORU YAMAGUCHI $^{1}$, KINRO SASAKI $^{1}$, \\ MAKOTO SAKAI $^{2}$, MAKOTO SOHDA ${ }^{2}$, TATSUYA MIYAZAKI ${ }^{2}$, HIROYUKI KUWANO ${ }^{2}$ and HIROYUKI KATO ${ }^{1}$ \\ ${ }^{1}$ Department of Surgery I, Dokkyo Medical University, Mibu, Japan; \\ ${ }^{2}$ Department of General Surgical Science (Surgery I), Gunma University, \\ Graduate School of Medicine, Maebashi, Japan
}

\begin{abstract}
Background/Aim: Adequate mediastinal lymphadenectomy during thoracoscopic esophagectomy (TE) requires an extensive operating field. In order to rectify this problem, we developed slender tracheal forceps that can pass through a 12-mm trocar. Patients and Methods: TE in the prone position was performed in 58 patients with esophageal cancer using slender tracheal forceps. Perioperative and postoperative clinical data were compared against those of 61 patients who underwent transthoracic open esophagectomy $(O E)$. Results: The mean duration of thoracic manipulation was significantly longer in the TE than OE group: 226.2 versus 171.3 minutes $(p<0.0001)$. Mean blood loss was significantly lower in the TE than OE group: 39.9 versus $176.8 \mathrm{~g}(p<0.0001)$. A mean of 23.4 mediastinal lymph nodes were dissected in the TE group and 25.1 in the OE group. The timing of extubation tended to be earlier in the TE group. Postoperative morbidity did not differ between groups. Conclusion: Slender tracheal forceps are acceptable for fine mediastinal lymphadenectomy in thoracoscopic surgery for esophageal cancer, and the technique could contribute to development of minimally invasive surgery.
\end{abstract}

Surgery for esophageal cancer is time-consuming and complicated. The three most common techniques for thoracic esophagectomy are the transhiatal approach, Ivor Lewis

Correspondence to: Masanobu Nakajima, MD, Ph.D., FACS, Department of Surgery I, Dokkyo Medical University, 880 Kitakobayashi, Mibu, Shimotsuga-gun, Tochigi 321-0293, Japan. Tel: +81 282872157, Fax: +81 282866213, e-mail: mnakajim@dokkyomed.ac.jp

Key Words: Esophageal cancer, thoracoscopic esophagectomy, lymphadenectomy, minimal invasive surgery, prone position. esophagectomy (right thoracotomy and laparotomy), and the McKeown technique (right thoracotomy followed by laparotomy and neck incision with cervical anastomosis) (1). In Japan, extended transthoracic esophagectomy with threefield lymphadenectomy (cervical, mediastinal and abdominal) with the McKeown technique has been performed for the past three decades (2). Although the prognosis of patients with esophageal cancer has improved as a result of such extensive surgery, postoperative morbidity and mortality are important problems that remain to be resolved $(3,4)$.

Recently, thoracoscopic esophagectomy (TE) has become more popular among surgeons, with an expectation that it will become a minimally invasive procedure (5). Although its consideration as a minimally invasive surgical technique is controversial (6), it seems to be equal or superior to conventional transthoracic surgery for anatomical recognition because of its magnified field of view (7). For TE to become a standard operating procedure, sufficient lymphadenectomy is required.

In esophageal cancer surgery, removal of the upper mediastinal lymph nodes, especially those of the right and left recurrent nerves, is important because of their high rate of metastasis (8). For adequate mediastinal lymph node dissection, an extensive operating field is required, and appropriate devices are needed to achieve this.

At our Institute, TE in the prone position has been performed for early-stage cancer. This approach is beneficial for surgeons because an adequate surgical field can be obtained without assistance, and it can provide surgeons with superior ergonomics for the left lateral position (9). However, the difficulty of lymph node dissection in the upper mediastinum, especially on the left side of the trachea, has been reported (10). In order to rectify this problem, we developed slender tracheal forceps that can pass through a $12-\mathrm{mm}$ trocar and create an adequate operating field. 
In this study, we investigated the effectiveness of this forceps and its suitability in TE.

\section{Patients and Methods}

Patients. From January 2011 to October 2014, 172 patients with esophageal cancer underwent esophagectomy at Dokkyo Medical University Hospital, Japan. We excluded patients who underwent transhiatal esophagectomy (40 cases), salvage esophagectomy (eight cases) and cervical esophagectomy including laryngopharyngoesophagectomy (five cases). Patients who underwent TE or transthoracic subtotal esophagectomy were eligible. TE with mediastinal lymphadenectomy in the prone position was performed in 58 patients with thoracic or abdominal esophageal cancer (TE group). The selection criteria for TE were as follows: no previous thoracic surgery; no possibility of severe pleural adhesion; and no previous (chemo-) radiotherapy of the esophagus. For the first 40 cases, this procedure was performed in patients with clinical T1/T2, N0 esophageal cancer. After that, the indications were extended to T3 and N1-3. In the same period, 61 patients underwent transthoracic open esophagectomy $(\mathrm{OE}$ group). The indications for transthoracic open esophagectomy were clinical T1-4a/N0-3 esophageal cancer (Table I).

The patients were staged according to the TNM classification (seventh edition) of the American Joint Committee on Cancer and the International Union Against Cancer (11). Informed consent for the operations was obtained from all patients according to our institutional guidelines.

Thoracoscopic surgery. The patients were intubated with a singlelumen endotracheal tube, and a blocking balloon was inserted into the right main bronchus to deflate the right lung. The patients were placed in the prone position. The first thoracoscopic port (12-mm Xcel port; ETHICON, New Brunswick, USA) was inserted at a posterior axillary line at the seventh intercostal space, and inflated with $\mathrm{CO} 2$ at $6 \mathrm{~mm} \mathrm{Hg}$, which collapsed the right lung. Next, another $12-\mathrm{mm}$ port was inserted at the scapular angle line at the ninth intercostal space. This port was used as the main observation port. Thereafter, three ports were arranged as follows: a $12-\mathrm{mm}$ port at the middle axillary line at the third intercostal space; a $12-\mathrm{mm}$ port at the posterior axillary line at the fifth intercostal space; and a 5-mm port at the scapular angle line at the seventh intercostal space. TE was started with mobilizing the upper esophagus with the regional lymph nodes. In order to mobilize the upper esophagus, the azygos vein and the right bronchial artery were divided. The upper mediastinal pleura was dissected and the upper thoracic esophagus, right main branch of the vagal nerve and right subclavian artery were exposed. After that, the right recurrent nerve lymph nodes were dissected up to the thyroid gland. We utilized a slender tracheal forceps (total length: $400 \mathrm{~mm}$, length excluding handgrip: 290 $\mathrm{mm}$, length of head: $43 \mathrm{~mm}$, maximum diameter of head: $8 \mathrm{~mm}$ ) that we developed ourselves (Figure 1). Moderate traction of the subclavian artery using this forceps allowed effective visualization of the surgical site (Figure 2). The upper thoracic esophagus was circumferentially mobilized and taped to allow moderate retraction. This tape was grasped by a Mini Loop Retractor II (COVIDIEN JAPAN, Tokyo, Japan) inserted through the chest wall at the inside of the right scapula. The upper thoracic esophagus was retracted to the dorsal side by pulling up the retractor. The adjacent trachea was rolled to the right and
Table I. Patient characteristics of thoracoscopic esophagectomy (TE) and transthoracic open esophagectomy (OE) groups.

\begin{tabular}{|c|c|c|c|}
\hline Factor & $\begin{array}{c}\text { TE group } \\
(\mathrm{n}=58)\end{array}$ & $\begin{array}{l}\text { OE group } \\
(\mathrm{n}=61)\end{array}$ & $p$-Value \\
\hline Age $($ mean \pm SD $)$ & $65.95 \pm 8.23$ & $63.82 \pm 9.36$ & 0.1911 \\
\hline Gender $(M / F)$ & $49 / 9$ & $49 / 12$ & 0.7220 \\
\hline Tumor location & & & 0.9947 \\
\hline Upper thoracic & 7 & 7 & \\
\hline Mid thoracic & 32 & 34 & \\
\hline Lower thoracic & 19 & 20 & \\
\hline Depth of tumor invasion & & & $<0.0001$ \\
\hline T0 & 0 & 1 & \\
\hline $\mathrm{T} 1$ & 43 & 6 & \\
\hline $\mathrm{T} 2$ & 7 & 6 & \\
\hline $\mathrm{T} 3$ & 7 & 40 & \\
\hline $\mathrm{T} 4$ & 1 & 8 & \\
\hline Lymph node metastasis & & & $<0.0001$ \\
\hline NO & 44 & 20 & \\
\hline $\mathrm{N} 1$ & 8 & 17 & \\
\hline $\mathrm{N} 2$ & 4 & 13 & \\
\hline N3 & 2 & 11 & \\
\hline Distant metastasis & & & 0.9713 \\
\hline M0 & 57 & 60 & \\
\hline M1 (Lym) & 1 & 1 & \\
\hline Stage & & & $<0.0001$ \\
\hline 0 & 0 & 1 & \\
\hline I & 42 & 8 & \\
\hline II & 8 & 10 & \\
\hline III & 7 & 41 & \\
\hline IV & 1 & 1 & \\
\hline Histology & & & 0.0381 \\
\hline Squamous cell carcinoma & 49 & 53 & \\
\hline Barrett adenocarcinoma & 5 & 1 & \\
\hline Adenocarcinoma & 0 & 5 & \\
\hline Other & 4 & 2 & \\
\hline Chemotherapy (yes/no) & $4 / 54$ & $26 / 35$ & $<0.0001$ \\
\hline
\end{tabular}

F: Female; M: male; SD: standard deviation; Lym: lymph node.

ventrally by the tracheal forceps (Figure 3 ). Tissue including the left recurrent nerve lymph nodes was radically dissected from this extended surgical site. In the middle mediastinum, the bilateral esophageal branch of the vagal nerve was divided, while the pulmonary branches were preserved. The subcarinal and bilateral main bronchial lymph nodes were dissected with the middle esophagus. In the lower mediastinum, the esophagus and regional lymph nodes were dissected along the layer that exposed the pericardium, descending aorta and left mediastinal pleura. After complete dissection of the thoracic esophagus and regional lymph nodes, a $24 \mathrm{Fr}$ chest drainage tube was inserted through the $12-\mathrm{mm}$ port site at the ninth intercostal space.

Perioperative and postoperative clinical course. The duration and blood loss of thoracic surgery were measured in the TE and OE groups, along with the number of dissected mediastinal lymph nodes. Additionally, we noted the duration of intubation, intensive care unit (ICU) stay, and postoperative hospital stay. Postoperative morbidity was assessed according to the Clavien-Dindo 
A

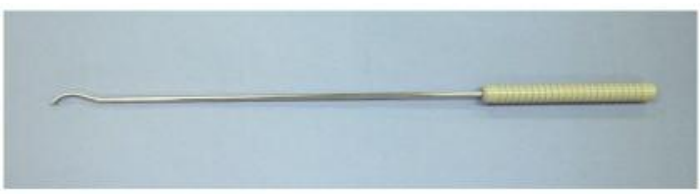

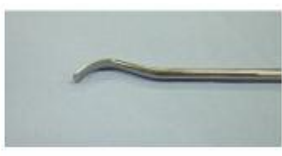

B

Figure 1. Slender tracheal forceps made at our institution. A: Complete view of the forceps. B: Magnified view of the head of the forceps. The obtuse angle allows gentle exclusion and traction of the trachea. This is appropriate as an artery or nerve exclusion forceps.

classification (12), and complications greater than grade II were regarded as significant. Surgical mortality (Clavien-Dindo grade V) included in-hospital deaths (by postoperative day 90).

Statistical analysis. Categorical analysis of variables was performed using either the Chi-square of Fisher's exact test, as appropriate. Continuous data were compared with the Mann-Whitney $U$-test. Differences were considered to be significant if the $p$-value was less than 0.05 . All statistical analyses were carried out using $\mathrm{R}$ software (version 3.1.1).

\section{Results}

Perioperative course. The surgical outcomes of esophagectomy are described in Table II. The duration of thoracic manipulation in the TE group was significantly longer than that in the OE group $(p<0.0001)$ at a mean of 226.2 minutes compared to 171.3 minutes in the OE group. Mean blood loss was $39.9 \mathrm{~g}$ in the TE group, compared with $176.8 \mathrm{~g}$ in the OE group $(p<0.0001)$. Although there was a tendency towards less frequent blood transfusion in the TE group, it was not significant. There were a mean 23.2 mediastinal lymph nodes dissected in the TE group and 24.8 in the $\mathrm{OE}$ group. There was no significant difference between the groups ( $p=0.1083)$. There was a mean of 4.2 left recurrent nerve lymph nodes dissected in the TE group and 4.5 in the OE group, but this difference was not significant $(p=0.4885)$. In the TE group, the mean duration of intubation was 0.03 days, compared with 0.33 days in the OE group. Although the difference was not significant, there was a tendency toward earlier extubation in the TE group $(p=0.0667)$. With regard to ICU stay and postoperative hospital stay, there were no significant differences between the groups ( $p=0.4980$ and $p=0.2066$, respectively).

Postoperative morbidity and mortality. There was no postoperative mortality. The incidence of postoperative morbidity did not differ significantly between the groups. Each complication was analyzed according to the ClavienDindo classification (Table III). With regard to recurrent nerve palsy, grade I or more dysfunction is shown. For other complications, including pneumonia, arrhythmia, anastomotic leakage and wound infection, those over grade II are shown. The most frequent complications for the whole

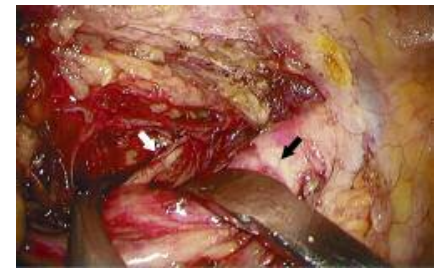

Figure 2. Photograph of lymph node dissection of the right recurrent nerve (white arrow) using a slender tracheal forceps. By excluding the right subclavian artery (black arrow) ventrally, a sufficient surgical view is obtained.

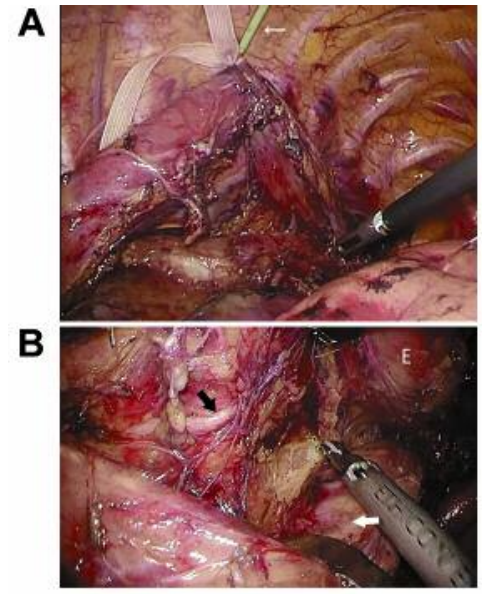

Figure 3. Photograph of lymph node dissection of the left recurrent nerve (black arrow) using a slender tracheal forceps and Mini loop retractor II. A: Mediastinal tissue, including left recurrent nerve, was extended by pulling the upper esophagus to the dorsal side using a Mini Loop Retractor II. (B) As a result of traction of the trachea to the ventral and right side, clear view around the left recurrent nerve is obtained. White arrow, trachea; E, esophagus.

cohort were recurrent nerve palsy and anastomotic leakage. The two groups did not differ significantly in regard to frequency of complications. Wound infection did not occur in these two groups. One patient each in the OE group had pyothorax and pleuritis. 
Table II. Surgical outcomes of thoracoscopic esophagectomy (TE) and transthoracic open esophagectomy (OE) groups.

\begin{tabular}{lccc}
\hline & TE group $(\mathrm{n}=58)$ & OE group $(\mathrm{n}=61)$ & $p$-Value \\
\hline Duration of thoracic manipulation (mean $\pm \mathrm{SD})(\mathrm{min})$ & $226.22 \pm 35.81$ & $171.25 \pm 35.40$ & $<0.0001$ \\
Blood loss in thoracic cavity (mean $\pm \mathrm{SD})(\mathrm{g})$ & $39.86 \pm 56.10$ & $176.82 \pm 131.07$ & $11 / 50$ \\
Blood transfusion (yes/no) & $4 / 54$ & $24.82 \pm 5.47$ & 0.0001 \\
No. of dissected mediastinal nodes (mean $\pm \mathrm{SD})$ & $23.17 \pm 5.64$ & $4.49 \pm 2.17$ & 0.1083 \\
No. of dissected left recurrent nerve nodes (mean $\pm \mathrm{SD})$ & $4.24 \pm 1.72$ & $0.328 \pm 1.193$ & 0.4885 \\
Intubation time (d) & $0.034 \pm 0.184$ & $1.082 \pm 0.918$ & 0.0667 \\
ICU stay (d) & $1.000 \pm 0.000$ & 20.8 & 0.4980 \\
Hospital stay (d) & 16.8 & & 0.2066 \\
\hline
\end{tabular}

ICU: Intensive care unit; SD: standard deviation.

\section{Discussion}

Thoracoscopic surgery for esophageal cancer is often performed as a type of minimally invasive surgery (13-17). Although its importance as a minimally invasive procedure has been controversial to date, the reduction in blood loss that results from being able to recognize fine structure is a merit of thoracoscopic surgery (18). Additionally, precise lymph node dissection may be possible because of the ability to view the fine structure (7). Recently, many institutions have introduced TE, especially in Japan and East Asia. However, more effective devices to enable sufficient lymphadenectomy and less invasiveness will be required if thoracoscopic surgery is to become a gold standard method of esophagectomy.

Among the mediastinal lymph nodes, those of the right and left recurrent nerves are important targets for lymphadenectomy because metastasis is frequent in these areas (19-21). In order to create an adequate operating field, we developed slender tracheal forceps.

TE is performed with the patient in the left lateral decubitus position (22-24) or prone position $(9,25-27)$. At our institute, we select to perform TE with the patient in the prone position because of its convenience for effective visualization of the mediastinum, and because accumulation of blood in the operating field is rare. However, the prone position is thought to be inferior to the left lateral position regarding left upper mediastinal lymph node dissection because effective visualization of the surgical field is difficult. Our method using slender tracheal forceps and Mini Loop Retractor II have an advantage of visualization of the surgical field derived from retraction and extension of the trachea and esophagus. For retraction of the trachea, endoscopic gauze or dissectors are generally used. However, it is easy for these instruments to slip on the membranous portion of the trachea. Therefore, frequent modification of retraction is necessary. There is rarely a need for modification of tracheal exclusion using our method. With regard to the Mini Loop Retractor II, which is a type of
Table III. Postoperative morbidity of thoracoscopic esophagectomy (TE) and transthoracic open esophagectomy $(O E)$ groups.

\begin{tabular}{lccl}
\hline & $\begin{array}{c}\text { TE group } \\
(\mathrm{n}=58)\end{array}$ & $\begin{array}{c}\text { OE group } \\
(\mathrm{n}=61)\end{array}$ & $p$-Value \\
\hline Morbidity $^{\mathrm{a}}$ & $21(36.2 \%)$ & $26(42.6 \%)$ & 0.4742 \\
Recurrent nerve palsyb & $12(20.7 \%)$ & $13(19.7 \%)$ & 0.9337 \\
Pneumonia & $3(5.2 \%)$ & $4(6.6 \%)$ & 0.7483 \\
Arrhythmia & $3(5.2 \%)$ & $3(4.9 \%)$ & 0.9495 \\
Anastomotic leakage & $8(13.8 \%)$ & $9(14.8 \%)$ & 0.8810 \\
Wound infection & $0(0 \%)$ & $0(0 \%)$ & - \\
Other & $0(0 \%)$ & $2(3.3 \%)$ & - \\
\hline
\end{tabular}

aver Clavien-Dindo classification grade II; bgreater than ClavienDindo classification grade I.

needle device (28), it is useful to pull the esophagus to the dorsal side, and to make a good operating field. Using these devices fully, an effective operating field is exposed for sufficient upper mediastinal lymphadenectomy.

Apart from effective lymph node dissection, prevention of postoperative mortality is a requirement of thoracoscopic surgery. Thoracoscopic surgery can minimize damage to the thoracic wall and preserve the respiratory muscles (7). Additionally, the magnified field of view allows for preservation of the minute vessels around the trachea or bronchus. In particular, a lateral longitudinal anastomosis, derived from the inferior thyroid artery, subclavian artery, internal thoracic artery, tracheoesophageal artery, and costocervical trunk, is important for tissue blood supply in the trachea (29). For the thoracoscopic technique, we can confirm lateral longitudinal anastomosis and dissect the lymph nodes around the trachea without injury. Our slender tracheal forceps are helpful for preservation of the lateral longitudinal anastomosis.

The point needing improvement for TE is shortening the long operative time. One report has highlighted the necessity for a specialist team comprising three experts (namely a 
surgeon, an assistant, and an endoscopist) for smooth TE (27). In our study, the operating time for mediastinal manipulation was significantly longer than that required for transthoracic surgery. One reason for this is that endoscopists are changed at regular intervals (e.g. every 3 months). Unlike transthoracic surgery, the skill of the endoscopist is important in thoracoscopic surgery. Optimal visualization depends on the endoscopist securing an effective visual field. Therefore, the education of endoscopists is one of the most important issues for effective thoracoscopic surgery. If standardization of the thoracoscopic procedure is achieved by skillful endoscopists and effective devices for surgical field extension are available, shorter operating times will be possible.

\section{Conclusion}

In conclusion, our procedure using slender tracheal forceps is acceptable for fine mediastinal lymphadenectomy in thoracoscopic surgery for esophageal cancer. We believe that the dissemination of these procedures could contribute to further development of minimally invasive surgery for esophageal cancer.

\section{Conflicts of Interest}

Masanobu Nakajima and other co-authors have no conflict of interest.

\section{Acknowledgements}

The Authors would like to thank Hitomi Ozeki, Yuki Ohashi and Nozomi Yuzawa for their skilful assistance.

\section{References}

1 Kato H, Fukuchi M, Miyazaki T, Nakajima M, Tanaka N, Inose T, Kimura H, Faried A, Saito K, Sohda M, Fukai Y, Masuda N, Manda R, Ojima H, Tsukada K and Kuwano H: Surgical treatment for esophageal cancer. Current issues. Dig Surg 24: 88-95, 2007.

2 Nakajima $\mathrm{M}$ and Kato $\mathrm{H}$ : Treatment options for esophageal squamous cell carcinoma. Expert Opin Pharmacother 14: 1345$1354,2013$.

3 Bhayani NH, Gupta A, Dunst CM, Kurian AA, Reavis KM and Swanström LL: Esophagectomies with thoracic incisions carry increased pulmonary morbidity. JAMA Surg 148: 733-738, 2013.

4 D'Amico TA: Mckeown esophagogastrectomy. J Thorac Dis Suppl 3: S322-324, 2014.

5 Kuwano H, Fukuchi M and Kato H: Thoracoscopic surgery for esophageal cancer. Ann Thorac Cardiovasc Surg 12: 305-307, 2006.

6 Kuwano H, Nishimura Y, Oyama T, Kato H, Kitagawa Y, Kusano M, Shimada H, Takeuchi H, Toh Y, Doki Y, Naomoto Y, Matsubara $H$, Miyazaki $T$, Muto $M$ and Yanagisawa $A$ : Guidelines for Diagnosis and Treatment of Carcinoma of the Esophagus April 2012 edited by the Japan Esophageal Society. Esophagus 12: 1-30, 2015.
7 Osugi H, Takemura M, Lee S, Nishikawa T, Fukuhara K, Iwasaki $\mathrm{H}$ and Higashino $\mathrm{M}$ : Thoracoscopic esophagectomy for intrathoracic esophageal cancer. Ann Thorac Cardiovasc Surg 11: 221-227, 2005

8 Miyata H, Yamasaki M, Makino T, Miyazaki Y, Takahashi T, Kurokawa Y, Nakajima K, Takiguchi S, Mori M and Doki Y: Therapeutic value of lymph node dissection for esophageal squamous cell carcinoma after neoadjuvant chemotherapy. J Surg Oncol 112: 60-65, 2015.

9 Palanivelu C, Prakash A, Senthilkumar R, enthilnathan P, Parthasarathi R, Rajan PS and Venkatachlam S. Minimally invasive esophagectomy: thoracoscopic mobilization of the esophagus and mediastinal lymphadenectomy in prone positionexperience of 130 patients. J Am Coll Surg 203: 7-16, 2006.

10 Kaburagi T, Takeuchi H, Kawakubo H, Omori T, Ozawa S and Kitagawa Y: Clinical utility of a novel hybrid position combining the left lateral decubitus and prone positions during thoracoscopic esophagectomy. World J Surg 38: 410-418, 2014.

11 Sobin LH GM and Wittekind CH (eds.): TNM Classification of Malignant Tumours. Seventh Edition. Wiley-Blackwell, United Kingdom, 2009.

12 Dindo D, Demartines $\mathrm{N}$ and Clavien PA: Classification of surgical complications: a new proposal with evaluation in a cohort of 6336 patients and results of a survey. Ann Surg 240: 205-213, 2004.

13 Iwahashi M, Nakamori M, Nakamura M, Ojima T, Katsuda M, Iida $\mathrm{T}$, Hayata $\mathrm{K}$ and Yamaue $\mathrm{H}$ : Clinical benefits of thoracoscopic esophagectomy in the prone position for esophageal cancer. Surg Today 44: 1708-1715, 2014.

14 Tapias LF and Morse CR: A preliminary experience with minimally invasive Ivor Lewis esophagectomy. Dis Esophagus 25: 449-455, 2012.

15 Cadière GB, Dapri G, Himpens $J$ and Rajan A: Thoracoscopic esophagectomy in prone position. Ann Surg Oncol 18: 838, 2011.

16 Noshiro H and Miyake S: Thoracoscopic esophagectomy using prone positioning. Ann Thorac Cardiovasc Surg 19: 399-408, 2013.

17 Chen B, Zhang B, Zhu C, Ye Z, Wang C, Ma D, Ye M, Kong M, Jin J, Lin J, Wu C, Wang Z, Ye J, Zhang J and Hu Q: Modified McKeown minimally invasive esophagectomy for esophageal cancer: a 5-year retrospective study of 142 patients in a single institution. PLoS One 8: e82428, 2013.

18 Tanaka E, Okabe H, Kinjo Y, Tsunoda S, Obama K, Hisamori S and Sakai Y: Advantages of the prone position for minimally invasive esophagectomy in comparison to the left decubitus position: better oxygenation after minimally invasive esophagectomy. Surg Today 45: 819-825, 2015.

19 Li B, Chen H, Xiang J, Zhang Y, Kong Y, Garfield DH and Li $\mathrm{H}$ : Prevalence of lymph node metastases in superficial esophageal squamous cell carcinoma. J Thorac Cardiovasc Surg 146: 1198-1203, 2013.

20 Hsu PK, Huang CS, Hsieh CC, Wu YC and Hsu WH: Role of right upper mediastinal lymph node metastasis in patients with esophageal squamous cell carcinoma after tri-incisional esophagectomies. Surgery 156: 1269-1277, 2014.

21 Igaki H, Tachimori Y and Kato H: Improved survival for patients with upper and/or middle mediastinal lymph node metastasis of squamous cell carcinoma of the lower thoracic esophagus treated with 3-field dissection. Ann Surg 239: 483-490, 2004. 
22 Akashi T, Taneda I, Higuchi N, Kuriya Y, Kuramoto J, Toyoda $\mathrm{T}$ and Wakabayashi A: Thoracoscopic en bloc total esophagectomy with radical mediastinal lymphadenectomy. J Thorac Cardiovasc Surg 112: 1533-1540, 1996.

23 Osugi H, Takemura M, Higashino M, Takada N, Lee S and Kinoshita H: A comparison of video-assisted thoracoscopic oesophagectomy and radical lymph node dissection for squamous cell cancer of the oesophagus with open operation. $\mathrm{Br}$ J Surg 90: 108-113, 2003.

24 Ichikawa H, Miyata G, Miyazaki S, Onodera K, Kamei T, Hoshida T, Kikuchi H, Kanba R, Nakano T, Akaishi T and Satomi S: Esophagectomy using a thoracoscopic approach with an open laparotomic or hand-assisted laparoscopic abdominal stage for esophageal cancer: analysis of survival and prognostic factors in 315 patients. Ann Surg 257: 873-885, 2013.

25 Ozawa S, Ito E, Kazuno A, Chino O, Nakui M, Yamamoto S, Shimada $\mathrm{H}$ and Makuuchi $\mathrm{H}$ : Thoracoscopic esophagectomy while in a prone position for esophageal cancer: a preceding anterior approach method. Surg Endosc 27: 40-47, 2013.

26 Petri R, Zuccolo M, Brizzolari M, Rossit L, Rosignoli A, Durastante V, Petrin G, De Cecchis L and Sorrentino M: Minimally invasive esophagectomy: thoracoscopic esophageal mobilization for esophageal cancer with the patient in prone position. Surg Endosc 26: 1102-1107, 2012.
27 Shirakawa Y, Noma K, Maeda N, Katsube R, Tanabe S, Ohara T, Sakurama K and Fujiwara T: Assistant-based standardization of prone position thoracoscopic esophagectomy. Acta Med Okayama 68: 111-117, 2014.

28 Asao T, Yanagita Y, Nakamura J, Hosouchi Y, Takenoshita S and Nagamachi Y: Usefulness of a visceral mini-retractor accessible without trocar port during laparoscopic surgery. Surg Endosc 13: 91, 1999.

29 Salassa JR, Pearson BW and Payne WS: Gross and microscopical blood supply of the trachea. Ann Thorac Surg 24: 100-107, 1977
Received September 1, 2016

Revised October 16, 2016

Accepted October 20, 2016 